\title{
SIMULATION OF STORM SURGE EVENTS AT THE PORTUGUESE COAST (VIANA DO CASTELO)
}

\author{
MAVC, Araújo'; A, Trigo-Teixeira ${ }^{2}$ and A, Mazzolari ${ }^{3}$ \\ Instituto Superior Técnico \\ CEHIDRO, Dept. Civil Engineering and Architecture \\ Av. Rovisco Pais, 1049-001 Lisbon, Portugal

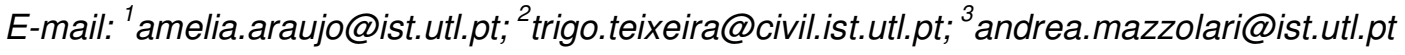

\begin{abstract}
An approach for simulating storm surge events was investigated and presented in this work. The storm surge event that occurred in the North of Portugal (Viana do Castelo), during the period of $14^{\text {th }}-16^{\text {th }}$ October 1987 was considered. In the definition of the computational domain, the path of the storm was considered, among other aspects. A tidal harmonic analysis was made to the tide gauge observations to extract the tidal components, enabling the determination of the sea level residuals. The ADCIRC model was used for the hydrodynamic modeling, which included different forcing mechanisms. Simulations were carried out for evaluating the model performance and to investigate possible nonlinear interactions between tidal and meteorological forcing. In this way, three types of simulations were carried out: modeling of the astronomical tides, with tidal forcing at the open boundary; modeling of the storm surge, using meteorological forcing only, and simulations including both tidal and meteorological forcing. Results show that there is some non-linear interaction between astronomical and meteorological forcing and that the observed sea levels are partially explained by this forcing. It was concluded that to obtain a better reproduction of the storm event, further simulations are required.
\end{abstract}

Keywords: storm surge simulation; sea level residuals; tide gauge records; inverse barometric effect; ADCIRC model; Viana do Castelo.

\section{Introduction}

There is evidence of elevated water levels along the Portuguese Atlantic coast and in some connected estuaries and lagoons. Some events have been recorded in tidal gauges showing levels exceeding the astronomical tide level in several tens of centimeters. On the other hand, there is also the perception that the frequency of the phenomenon is increasing in some low-lying places, mainly in the margins of estuaries and lagoons. Despite the fact that elevated water levels have been registered on the Portuguese coast, estuaries and lagoons, little is known about the forcing mechanisms and the relative importance of each of them mainly the role of storms. Besides, records are not long enough and measuring stations are scarcely distributed along coast and located mainly within harbors. Therefore, the use of a physics-based hydrodynamic model that can reproduce the sea surface elevation under astronomic and meteorological forcing is compulsory.

This work presents the preliminary results obtained in the simulation of a storm surge event that occurred in the North of Portugal (Viana do Castelo), during the period of $14^{\text {th }}-16^{\text {th }}$ October 1987 . This event was selected since it is a reference by its intensity and damage, 
especially in the U.K. and France. Some analysis of this storm surge, in Portugal, has been made by Gama et al. [1994].

In the present work, three types of simulations were carried out: modeling of the astronomical tides, with tidal forcing at the open boundary; modeling of the storm surge, using meteorological (wind and pressure) forcing only (tidal forcing is neglected); simulations including both tidal and meteorological forcing. Simulation results were used to investigate possible nonlinear interactions between tidal and meteorological forcing. Also, these results are compared with observed data at tide gauge records.

\section{Computational Domain and Mesh Generation}

The definition of the model domain was made considering, among other factors, the path of the storm. Fig. 1 shows the path of the $14^{\text {th }}-16^{\text {th }}$ October 1987 storm. In this figure it is evident the travel of the depression over the U.K., northern of France, the western Iberian coast, the coasts of Belgium and Holland, towards the North Sea loosing gradually strength.

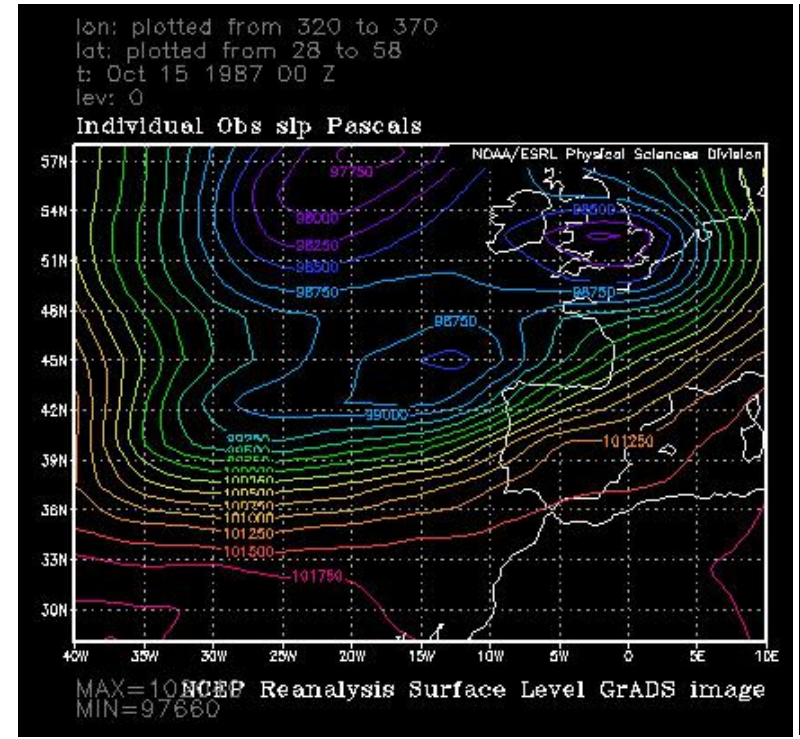

a)

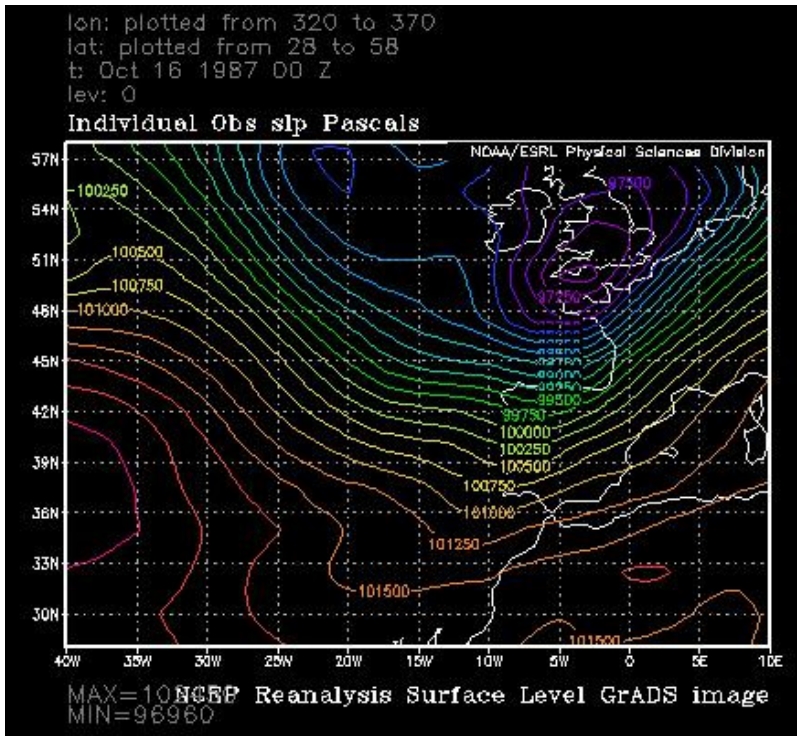

b)

Fig.1. Path of the 1987 storm: a) October $15^{\text {th }}$; b) October $16^{\text {th }}$ (Courtesy of the NOAA/ESRL Physical Sciences Division at http://www.esrl.noaa.gov/ with dataset source of Kalnay et al., 1996).

\subsection{Computational Domain and Digital Elevation Model}

One difficult task in modeling tide and storm surges is the boundary location: according to literature recommendations [Blain et al., 1994], it is good practice to locate the open ocean boundary in deep waters, without any possible interference with coastline and other topographic features, and where the tide and meteorological forcing are known. The chosen domain extends form 39.4 to $43.1^{\circ} \mathrm{N}$ and 8.67 to $16.19^{\circ} \mathrm{W}$ (Fig. 2). The land boundary was located along the coast, at a depth of $12 \mathrm{~m}$. The domain size and the boundary locations, both onshore and on the open ocean, should be seen as a first attempt to identify the minimum area which allows the model to capture the phenomena.

The digital elevation model (DEM), which was used for mesh generation, has different bathymetry sources. At the Portuguese/Spanish shelf, hydrographic charts (resolutions of 
$1: 150,000$ and $1: 1000,000$ ) published by the Portuguese Navy (Instituto Hidrográfico) were used. The contours of these charts were digitized from the coastline up to depths of $4000 \mathrm{~m}$. The bottom bathymetry for deep water was obtained from the world database of the Institute of Geophysics and Planetary Physics [Smith and Sandwell, 1997], with a grid resolution of 1 $\min$.

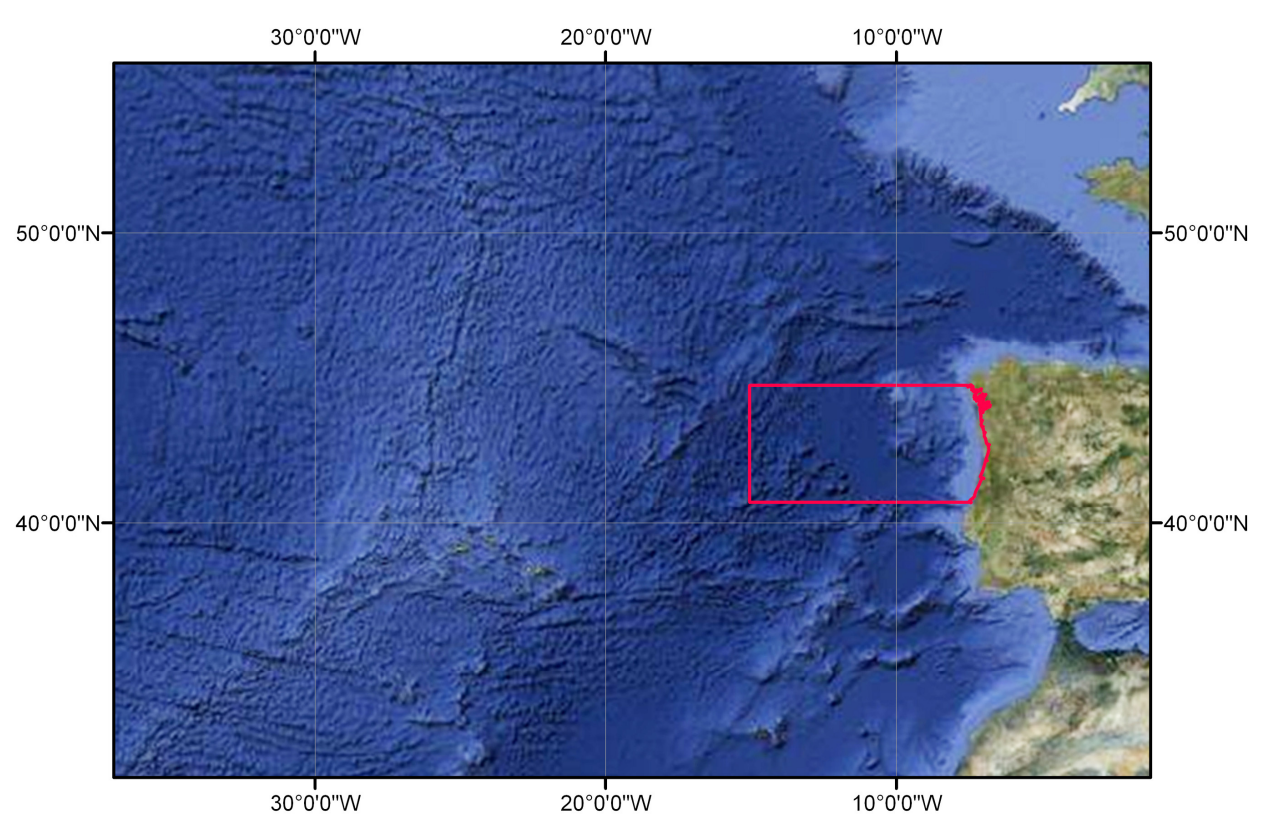

Fig.2. Computational domain, extending for $400 \mathrm{~km}$ along the west lberian Coast and $615 \mathrm{~km}$ across in the Atlantic Ocean.

\subsection{Mesh Generation}

The 2D Delaunay mesh generator Triangle, interfaced in the BatTri package [Bilgili et al., 2005], was used for the discretization of the computational domain. The methodology consisted in a series of successive refinements of an initial coarse mesh, applying each time a $h / A$ ratio criterion for a specific range of depths, where $h$ is the mean element depth and $A$ the element area. In this way, the grid is finest near the coast and in the presence of offshore sand banks (e.g. Galicia bank). With this technique of depth-dependent refinement, the final mesh was able to follow the isolines of the nautical charts. Attention was taken in assuring a smooth element grading from deep to shallow waters and in enhancing the resolution of the shelf break and continental slope, where higher bathymetry gradients are located. The spatial resolution of the mesh ranges from approximately $14.5 \mathrm{~km}$ offshore to $480 \mathrm{~m}$ near the coast (Fig. 3). A reference node in the mesh (reference station), located at approximately 2 $\mathrm{km}$ from the tide gauge and with a depth of $16 \mathrm{~m}$, was selected for later comparison of the observed sea levels at tide gauge with those obtained by the simulations and for comparison of all the results in the modeling tests. 


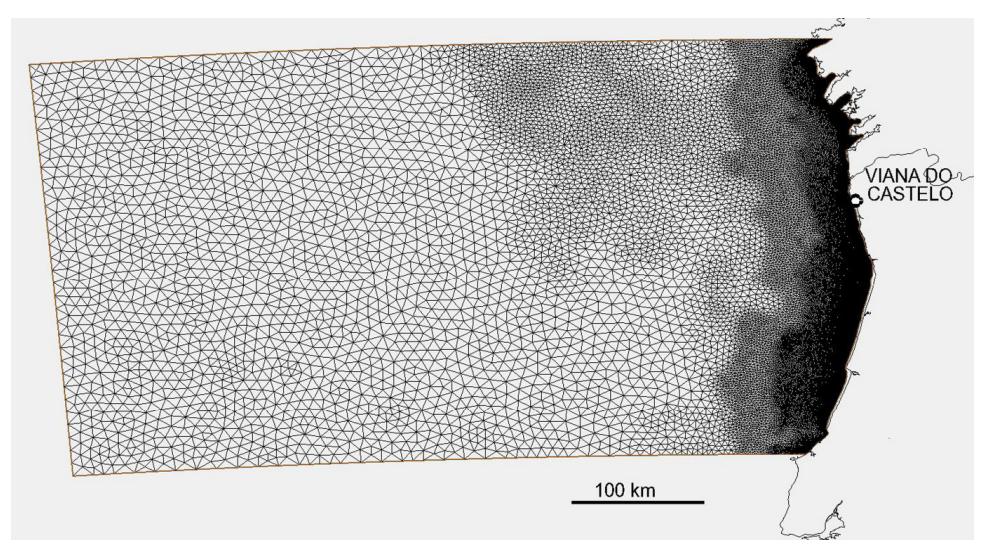

Fig.3. Unstructured triangular mesh generated for the computational domain, with 30360 nodes and 59527 elements.

\section{Tidal Harmonic Analysis}

Records from a tide gauge located in Viana do Castelo were used to identify the storm surge event. The tide gauge is located in the open coast (at port of Viana do Castelo, at the entrance of the Lima estuary). The data consisted of observed hourly values of sea level for the year of 1987 , which were submitted to a tidal harmonic analysis to remove the tidal components. Data ranging from January $1^{\text {st }}$ to April $3^{\text {rd }}$ were not considered due to tide gauge malfunction. The sea level residuals were obtained by the difference between the observed and predicted tidal levels (added with the average water level registered in 1987), enabling the easy identification of the surge. Tidal harmonic analysis was performed using the T-tide software [Pawlowicz et al., 2002], based on 37 constituents.

Fig.4 shows the observed and predicted tidal levels as well as the residuals, which correspond to the storm surge. It is observed a peak surge level of $80 \mathrm{~cm}$, which is comparable with the analysis of Gama et al. [1994].

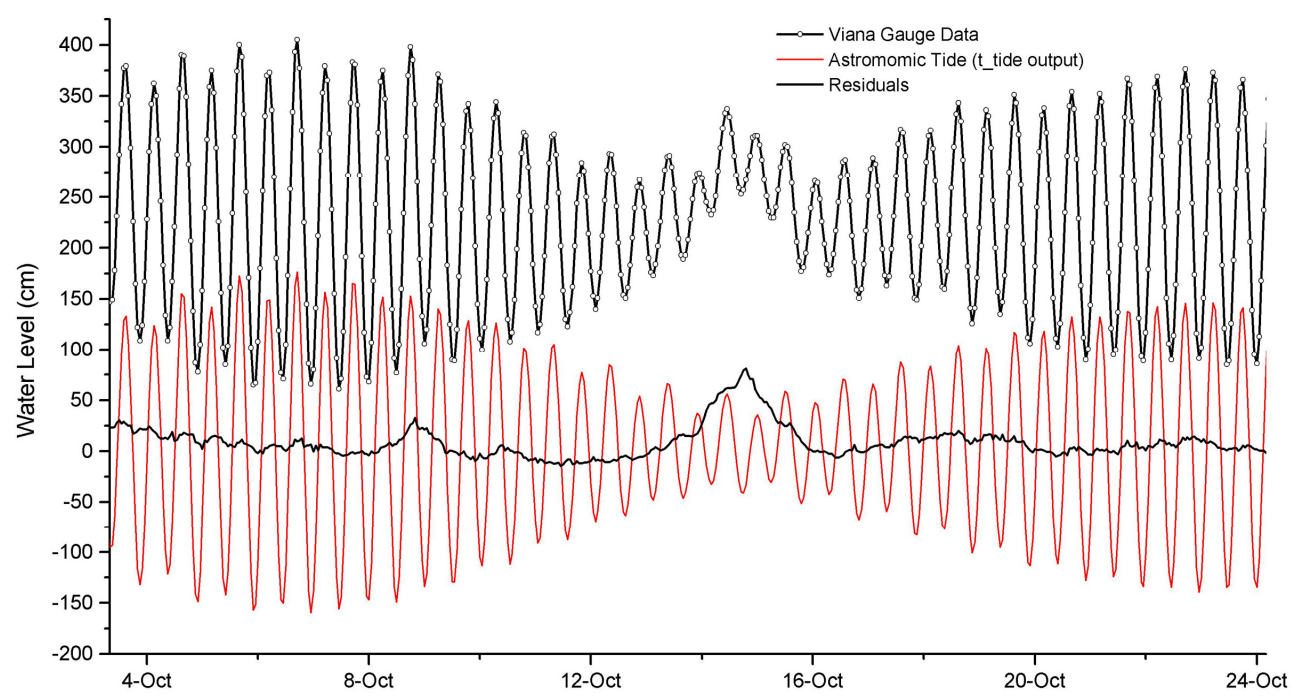

Fig. 4. Surge event at Viana do Castelo: $14^{\text {th }}-16^{\text {th }}$ October 1987. 


\section{Model and Data Sources}

\subsection{Hydrodynamic Model}

The circulation model ADCIRC (ADvanced CIRCulation Hydrodynamic Model) was used for the simulations. This model has been developed with a direct application on shelves, coasts and within estuaries [Luettich et al., 1992], to obtain long numerical simulations for very large computational domains and has been tested extensively. This is a finite element model, based on the generalized wave-continuity equation (GWCE), which solves the fully nonlinear, depth-averaged, shallow-water equations, expressing the conservation of mass and momentum under the conventional hydrostatic and Boussinesq approximations.

The model assumed a fixed land boundary, since that boundary was considered to be at 12 $\mathrm{m}$ in depth from the shore. Therefore, the possible wetting and drying problems were avoided. The software SMS (Surface-water Modeling System) was used as an interface of the numerical model.

\subsection{Data Sources for Astronomical and Meteorological Forcing}

The model provides the tide and storm related hydrodynamic forcings necessary for the domain. The tidal boundary conditions were obtained through an ADCIRC feature that imports the tidal harmonic constituents from an internal database - Le Provost database [Le Provost et al., 1995].

In the modeling of the storm surge, the hydrodynamic model was forced with near-surface winds, typically winds at $10 \mathrm{~m}$ above the surface, as suggested by other researchers [Mclnnes et al., 2009], and sea level pressure. This atmospheric forcing was obtained, for the selected storm surge event, from archived analysis of observed weather conditions from the US National Center for Environmental Prediction - NCEP/NCAR reanalysis [Kalnay et al., 1996]. The 4-times daily data was linearly interpolated in space and time, from the T62 Gaussian grid with $192 \times 94$ points $\left(1.875^{\circ} \times 1.875^{\circ}\right)$ for the wind fields and from the $25^{\circ} \mathrm{x}$ $2.5^{\circ}$ global grid (144x73) for the pressure, to the finite element mesh.

For the simulation of storm surge (forced by wind and pressure only), the open ocean boundary was forced by imposing an inverted barometer condition which considers the pressure component of the meteorological forcing. This boundary condition specification has been used by other researchers [Blain et al., 1994].

\section{$5 \quad$ Results and Discussion}

As mentioned before, this paper includes different types of simulations, depending on the forcing mechanism: tidal modeling, storm surge modeling and simulations including both tidal and meteorological forcing.

The model was run for 8 days and simulations were carried out using a ramp function of 2 days. A constant time step of $30 \mathrm{~s}$ was used to ensure that Courant numbers (based on wave celerity) are always well bellow 1 , providing model stability and accuracy. The bottom friction coefficient was set equal to $0.002 \mathrm{~s}^{-1}$ throughout the domain and the weighting factor in GWCE equations, $\tau_{0}$, was considered as 0.002 . 
Tidal simulations were carried out using open ocean boundaries forced with the $2 \mathrm{~N} 2, \mathrm{~K} 1, \mathrm{~K} 2$, L2, M2, MU2, N2, NU2, O1, P1, Q1 and S2 tidal constituents. Tidal potential forcing inside the domain was also applied for the same constituents. For the model validation, preliminary tests were carried out changing the formulation of "constant linear", "constant quadratic" or "constant hybrid" for the bottom friction coefficient and it was concluded that the first option produced a better fit to the tidal signal. Data from 1999 have been preferred because the hourly time series observations contain a limited number of gaps, assuring a more precise estimation of the harmonic constants. The time series of both computed surface elevations and synthesized surface elevations from harmonically decomposed measured constituent data (using exactly the same constituents) were compared. Fig. 5 shows the ADCIRC model performance by comparing those results, testing different values for the bottom friction coefficient. A coefficient of $0.002 \mathrm{~s}^{-1}$ was chosen as it offers the best phase fit.

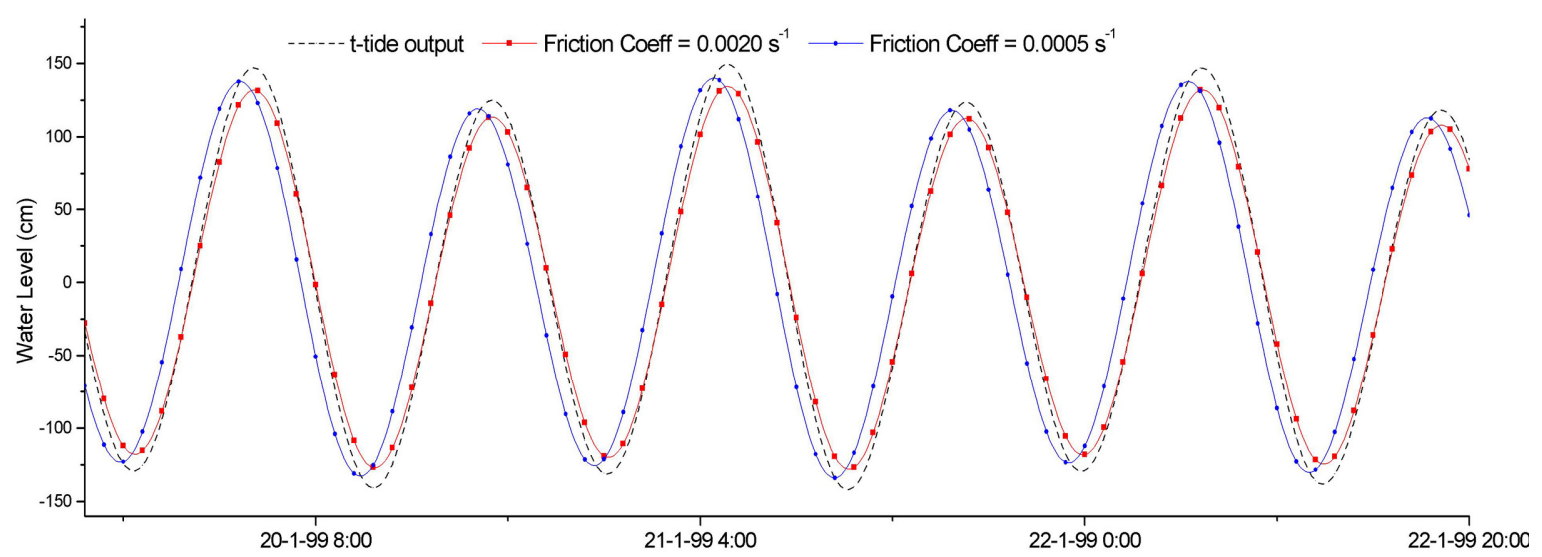

Fig.5. Calibration tests for the ADCIRC model using astronomical forcing for different "constant linear" bottom friction coefficient. The reference water level is given by the $t$ _tide astronomical output.

Fig.6 presents results related with the hydrodynamic modeling of the storm surge. This figure shows the input pressure field and the water elevations obtained by the simulation, for a few time steps during the course of the storm. It is evidenced the condition of the inverse barometric effect propagating along the domain during the storm: the red contours represent the water surface set-up moving accordingly to the depression field. The storm bulge seems to statically follow the pressure pattern and not to propagate as a wave from its generation point all over the rest of the domain. 

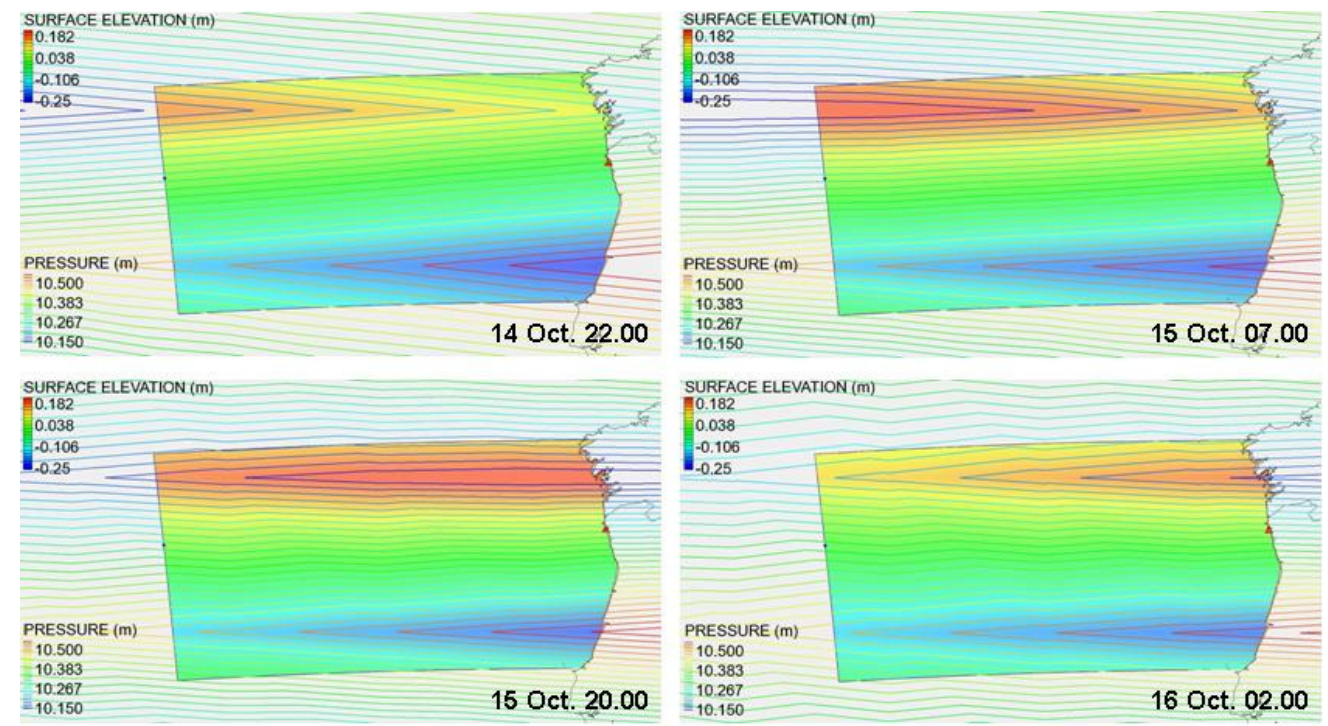

Fig.6. Sequence of frames showing the pressure field (background line contours) and the water elevation (contour fill) for the simulation with meteorological forcing only, during the passage of the storm.

Simulations including both tidal and meteorological forcing were also carried out. Fig. 7 presents the comparison of the computed storm tide curve (forced with both astronomical and meteorological mechanisms) with the curve obtained as the sum of the meteorological and astronomical forcing simulated separately. These results suggest that there is a certain nonlinear transfer of energy between tidal and meteorological forcings, for the present case of study. This means that tidal and storm surge dynamics are not completely independent. Moreover, this figure shows that, during the storm surge peak, the computed elevation is yet far from the total water level registered by the tide gauge for the event. In particular, the contribution of pressure and wind adds, at the peak point, only $4 \mathrm{~cm}$ to the astronomical tide elevation, while the surge has been estimated in the order of $80 \mathrm{~cm}$ (see Fig. 4).

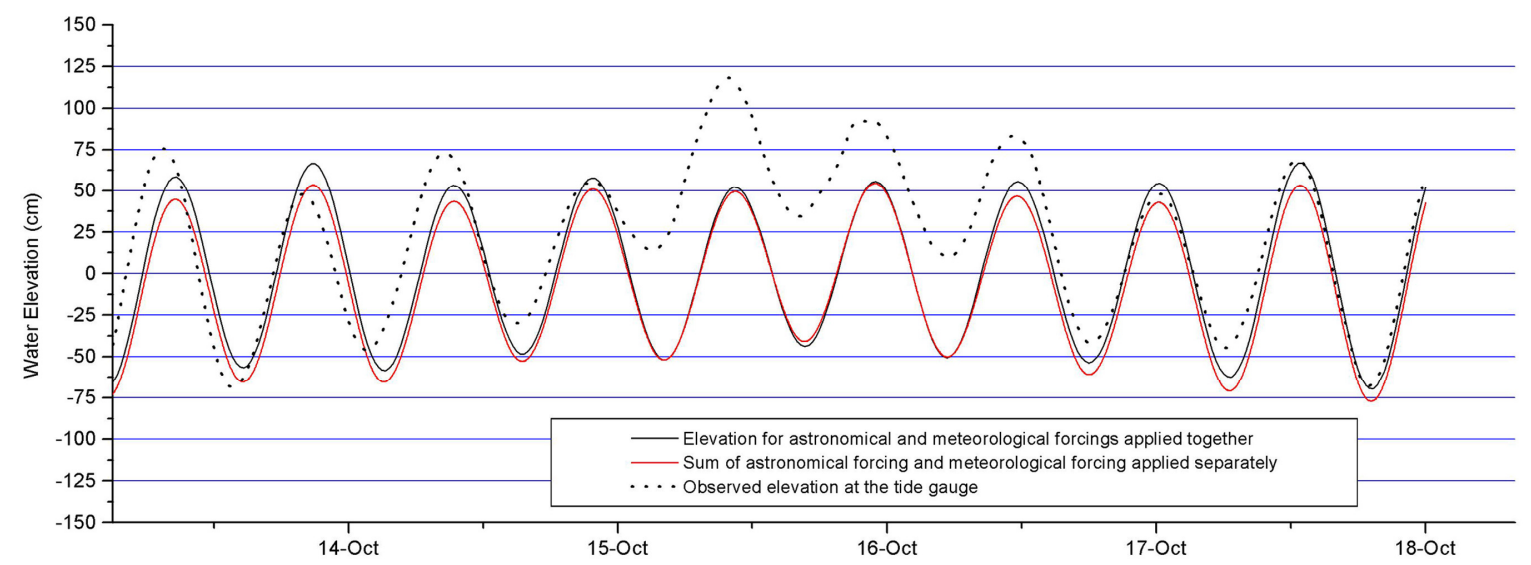

Fig.7. ADCIRC time series of the water surface elevation at the reference station for the astronomical and meteorological forcing together, and for sum of the astronomical and meteorological forcings computed in different runs. The target series is the observed sea levels at the tide gauge, normalized by the average water level. 
In order to evaluate the sensitivity of the model to wind forcing, various simulations were carried out using synthetic winds, with different intensity, blowing for 10 days perpendicularly to the coastline. These simulations considered also tidal forcing and the atmospheric pressure. It was verified that with winds blowing at $30 \mathrm{~m} / \mathrm{s}$, which is much above the wind velocity occurred along the domain during the storm period (around $6 \mathrm{~m} / \mathrm{s}$ ), the sea level elevations (residuals obtained by subtracting the elevations obtained by tidal simulations) were around $17 \mathrm{~cm}$. It was also verified that these elevations were negligible (around $1 \mathrm{~cm}$ ) when using wind velocities lower than $10 \mathrm{~m} / \mathrm{s}$. Probably, if the reference station was located in shallower waters, the wind effects would be more pronounced.

\section{Conclusions}

This paper presents an exercise of modeling storm surge events in the North coast of Portugal by means of the ADCIRC model. A well graded unstructured triangular grid was generated for a $400 \mathrm{~km} \times 615 \mathrm{~km}$ almost rectangular domain. A water depth condition equal to $12 \mathrm{~m}$ was considered at the coast boundary.

Test results obtained with the astronomical and meteorological forcing, first applied separately and then jointly, evidence the non-linear interaction between them. Taking this reference storm surge event, the results for the astronomical and meteorological forcing do not explain completely the observed sea levels. This may be for a number of reasons: an insufficient domain extension; a too deep coastal water depth which limits the wave propagation in shallow waters; a possible inconsistency in the available meteorological and gauge data; the absence of the wave set-up simulation; a too coarse grid refinement in the nearshore zone; the influence of river discharge on the observed data. Therefore, to obtain a better reproduction of the storm event, further simulations are required which should take into account the above mentioned causes.

\section{References}

Bilgili, A., Smith, K.W., and Lynch, D.R., 2005. BatTri: A 2-D Unstructured Grid Generator for Finite Element Circulation Modeling. Computers \& Geosciences, 32(5), 632-642.

Blain, C.A., Westerink, J. J. and Luettich R. A. Jr, 1994. The influence of domain size on the response characteristics of a hurricane storm surge model. J. Geophys. Res., 99 (C9), 18467-18479.

Gama, C., Dias, A., Ferreira, O. and Taborda, R., 1994. Analysis of storm surge in Portugal between June 1986 and May 1988. Littoral 94, Lisbon, 381-387.

Kalnay, E., Kanamitsu, M., Kistler, R., Collins, W., Deaven, D., Gandin, L., Iredell, M., Saha, S., White, G., Woollen, J., Zhu, Y., Leetmaa, A., Reynolds, B., Chelliah, M., Ebisuzaki, W., Higgins, W., Janowiak, J., Mo, K.C., Ropelewski, C., Wang, J., Jenne, R. and Joseph, D., 1996. The NCEP/NCAR 40-year reanalysis project. Bull Am Meteorol Soc., 77, 437-471.

Le Provost, Bennett, A.F., and Cartwright, D.E., 1995. Ocean tides for and from Topex/Poseidon. Science, 267 (5198), 639-647.

Luettich, R. A., Westerink, J. J., and Schefmer, N. W., 1992. ADCIRC: An advanced three-dimensional circulation model for shelves, coasts, and estuaries. Report 1: Theory and methodology of ADCIRC2DDI and ADCIRC-3DL. Technical Report DRP-92-6, U.S. Army Engineer Waterways Experiment Station, Vicksburg, MS. 
Mclnnes, K., Macadam, I., Hubbert, G., and O'Grady, J., 2009. A modelling approach for estimating the frequency of sea level extremes and the impact of climate change in southeast Australia. Nat. Hazards, 51, 115-137.

Pawlowicz, R.; Beardsley, B. and Lentz, S., 2002. Classical tidal harmonic analysis including error estimates in MATLAB using T-tide. Computers \& Geosciences, 28, 929-937.

Smith, W. and Sandwell, D., 1997. Global seafloor topography from satellite altimetry and ship depth soundings. Science, 277, 1957-1962, 26 Sept.

\section{Acknowledgements}

This work was funded by the Portuguese Foundation for the Science and Technology (FCT), through the Doctoral Grant of the second co-author (SFRH/BD/61161/2009).

The authors thank the Institute of Geophysics and Planetary Physics and the US National Center for Environmental Prediction (NCEP) for providing the data. 